\title{
Incidence and Course of Depression in Patients with Alzheimer's Disease
}

\author{
Seung-Ho Ryu', Han-Yong Jung ${ }^{2} \bowtie$, Kang Joon Lee ${ }^{3}$, Seok Woo Moon ${ }^{4}$, Dong Woo Lee ${ }^{5}$, \\ Narei Hong ${ }^{6}$, Baik Seok Kee ${ }^{7}$, Do Hoon Kim ${ }^{8}$, Changsu Han ${ }^{9}$, and Chang Uk Lee ${ }^{10}$ \\ 1'Department of Psychiatry, Konkuk University Medical Center, School of Medicine, Konkuk University, Seoul, Republic of Korea \\ ${ }^{2}$ Department of Psychiatry, Soonchunhyang University College of Medicine, Bucheon Hospital, Bucheon, Republic of Korea \\ ${ }^{3}$ Department of Psychiatry, College of Medicine, Inje University, Ilsan Paik Hospital, Goyang, Republic of Korea \\ ${ }^{4}$ Department of Konkuk University Chungju Hospital, School of Medicine, Konkuk University, Chungju, Republic of Korea \\ ${ }^{5}$ Department of Psychiatry, College of Medicine, Inje University, Sanggye Paik Hospital, Seoul, Republic of Korea \\ ${ }^{6}$ Department of Psychiatry, Hallym University Sacred Heart Hospital, Anyang, Republic of Korea \\ ${ }^{7}$ Departments of Psychiatry, Chung-Ang University, College of Medicine, Seoul, Republic of Korea \\ ${ }^{8}$ Department of Psychiatry, Korea University College of Medicine, Seoul, Republic of Korea \\ ${ }^{9}$ Department of Neuropsychiatry, Chuncheon Sacred Heart Hospital, Hallym University College of Medicine, Chuncheon, Republic of Korea \\ ${ }^{10}$ Department of Psychiatry, Seoul St. Mary's Hospital, The Catholic University of Korea, Seoul, Republic of Korea
}

Objective Depressive symptoms are common in Alzheimer's disease (AD) and they might influence the course and prognosis of AD. Depression could appear anytime in the course of the disease, and could either last considerably long or disappear easily. This study is intended to investigate the occurrence of depression in the course of $\mathrm{AD}$ and the risk factors of incidence.

Methods This study targeted 1,272 AD patients without depressive symptoms at the start of this study in Korea. A total of 775 subjects completed the study, and the occurrence of depression was assessed after 12 months. Demographic information of subjects was collected and cognitive functions, overall functions, and depression severity were assessed at the start of this study and after 12 months.

Results Among the 775 subjects, 103 subjects (13.29\%) developed depression 12 months later. The MMSE-KC scores showed significant changes in both groups that developed depression and did not. In the univariate analysis, significant differences in the incidence of depression were found in terms of gender, the administration of the antidepressant at the baseline, the SGDS-K score, and the GDS score. The multiple logistic regression analysis showed that the increase in the incidence of depression was associated with a female, in the increase in SGDS-K score and the GDS score.

Conclusion The incidence of depression in the subjects who completed the 12-month follow-up observation was $13.29 \%$. Moreover, in the multivariate analysis, a female gender and the severity of dementia, including the overall functions, seemed associated with the occurrence of depression.

Psychiatry Investig 2017;14(3):271-280

Key Words Depression, Incidence, Alzheimer's disease, Risk factors.

\section{INTRODUCTION}

Alzheimer's disease (AD) and depression are common mental health problems among the elderly. $\mathrm{AD}$, which is the most common degenerative brain disease that causes de-

Received: May 8, 2016 Accepted: May 26, 2016 Available online: February 27, 2017

$\triangle$ Correspondence: Han-Yong Jung, MD, PhD

Department of Psychiatry, Soonchunhyang University Bucheon Hospital, 170 Jomaru-ro, Wonmi-gu, Bucheon 14584, Republic of Korea

Tel: +82-32-621-5232, Fax: +82-32-621-6950, E-mail: hanyjung@schmc.ac.kr

(a) This is an Open Access article distributed under the terms of the Creative Commons Attribution Non-Commercial License (http://creativecommons.org/licenses/bync/4.0) which permits unrestricted non-commercial use, distribution, and reproduction in any medium, provided the original work is properly cited. mentia in the elderly, results in memory decline in its early stage. As time passes, it causes impairment through deteriorated cognitive functions in many areas. The disease is generally accompanied by various neuropsychiatric symptoms (NPSs). It is especially known to be accompanied by depressive symptoms in its early stage, ${ }^{1,2}$ but the association between the severity of $\mathrm{AD}$ and the prevalence of depression is not yet clear. ${ }^{3}$ Depression in $\mathrm{AD}$ is so common that its prevalence is up to approximately $50 \%$, but the rate may vary depending on the diagnostic method, degree of depression, and study population..$^{4-7}$ Additionally, according to a long-term prospective study, the occurrence of depression during the progress 
of dementia or mild cognitive impairment seems more common than in the general population. ${ }^{8}$

There are many clinically significant studies on the prevalence and progress of depression in $\mathrm{AD},{ }^{9}$ but studies on the incidence of depression are rare. Typical study results published up to now are the $1.3 \%$ incidence of major depressive disorder for two years in the series of studies of Weiner et al., ${ }^{10,11}$ which used a community database, and the $1.6 \%$ incidence per year in another study. In a study that targeted patients admitted to a nursing home for dementia patients, the incidence of depression appeared to have been $1.8 \%$ over six months and $6.4 \%$ over one year, which are somewhat higher. ${ }^{12}$ The incidence rates in the two aforementioned studies are the results of major depressive disorder. If mild depression is included, the incidence of depression will be higher. However, prospective hospital-based studies on the incidence of depression in $\mathrm{AD}$ patients who actually visit a hospital are insufficient.

The occurrence and presence of depression in $\mathrm{AD}$ may significantly affect the patient's function level and quality of life. Depression can directly influence the patient's actual function level by affecting his/her cognitive functions. In addition, the elderly with depression commonly complain of memory decline, so it is easy to confuse depression with $\mathrm{AD}$, but they may be separate diseases that should be differentiated. ${ }^{13,14}$ There have been many studies on the association of depression with cognitive functions and dementia, and the results are varied. ${ }^{15-19}$ Many studies have indicated that depression is a risk factor related to the occurrence of dementia, including AD. ${ }^{20-24}$ Depression is an important and relatively common symptom of dementia, including $\mathrm{AD}$, and affects the patient's general status. Additionally, depression has a good therapeutic response to medication, etc. compared to cognitive symptoms, so understanding its characteristics and managing it are very important. ${ }^{25}$

Since depression negatively influences $\mathrm{AD}$ patients in general, it will be important to identify the possibility of the occurrence of depression and the factors associated with such occurrence in $\mathrm{AD}$ patients who did not have depression. Doing this can provide $\mathrm{AD}$ patients' basic data for clinical approaches and treatments. Therefore, in this study, $\mathrm{AD}$ patients without depression were followed up for one year, and the frequency of depression was investigated. This study also sought to analyze the influence of depression on cognitive functions of $\mathrm{AD}$ patients as well as the possible risk factors of the occurrence of depression.

\section{METHODS}

\section{Subjects}

From October 25, 2011 to March 17, 2014, 1,272 subjects were consecutively recruited at 30 psychiatry departments of general hospitals in the Republic of Korea. Approval of the Institutional Review Board (IRB) was obtained from each institution before the study started. Among patients who were diagnosed with AD based on DSM-IV ${ }^{26}$ or NINCDS-ADRDA, ${ }^{27}$ this study targeted subjects who did not have any depressive episode at the start of this study and who were determined to have had no depressive episode. The Korean version of the Mini-International Neuropsychiatric Interview (MINI-K) was used as the interview tool. ${ }^{28}$ Patients who were unable to visit at the appropriate time during the study period, patients with a speech impediment to the extent that undergoing an examination was impossible, and patients without a caregiver who could provide information on whether depression occurred or not were excluded. At the start of this study, the subjects' detailed demographic information was collected, including their age, gender, weight, height, and education level; the date of their $\mathrm{AD}$ diagnosis, their comorbidity and medical history; and the current status of intake of prescription drugs, including cognitive enhancers and other psychotropic drugs.

These subjects were followed up for 12 months, and the occurrence of depression, their cognitive functions, the severity of their depressive symptoms, and their overall dementia status were measured for a total of 3 times at the baseline and after 6 months and 12 months. Tools used were MINI-K, the Korean version of the Geriatric Depression Scale-Short Form (SGDS-K), ${ }^{29}$ the Korean version of the Mini-Mental-State Examination in the CERAD-K (MMSE-KC), ${ }^{30}$ and the Global Deterioration Scale (GDS). ${ }^{31}$ Finally, the changes from the baseline after 12 months were evaluated.

\section{Assessment of depression}

\section{MINI-K}

MINI is a structured interview developed by Sheehan et al. ${ }^{32}$ in 1998 to diagnose mental disorders in the field of psychiatry. Mental health professionals conduct many structured interviews to standardize diagnosis, but most of them require too much time to apply in a real situation. MINI can be conducted after minimal training, takes only about 15 minutes, and is a simple and effective interview, so it is suitable for the elderly or dementia patients who cannot endure a long interview. It is a tool with high utilization in research or clinical practice because it considers the diagnostic criteria of ICD-10 ${ }^{33}$ or DSM-IV. ${ }^{26}$ Therefore, in this study, the MINI-K standardized in Korean in 2006 was used.

\section{SGDS-K}

SGDS (Geriatric Depression Scale-Short Form) was developed as a brief form of a 30-item Geriatric Depression Scale (GDS), which is the most widely used for screening elderly 
depression worldwide. ${ }^{34,35}$ Compared to the original, the brief form containing only 15 items is easy to apply and is known to have appropriate reliability and validity in diagnosing elderly depression. In this study, the SGDS-K standardized in Korean in 2004 was used. ${ }^{29}$

\section{Assessment of cognitive functions and the stage of dementia}

\section{MMSE-KC}

Mini-Mental State Examination (MMSE) ${ }^{36}$ is a tool for assessing overall cognitive functions. It is frequently used to screen dementia. The MMSE score ranges from 0 to 30: the higher the score is, the better the cognitive functions are. In this study, the MMSE-KC standardized in Korean was used..$^{30}$ The MMSE-KC score differs greatly depending on the educational attainment or age of the subject. Thus, the damage to cognitive functions is assessed by suggesting the normative score depending on the age, education, and gender.

\section{GDS}

GDS was designed to provide rough information to caregivers on the stage of the overall function level based on the damage in the cognitive functions of the patients affected by primary degenerative dementia, such as $\mathrm{AD} .^{31}$ It is divided into 7 stages: stages $1-3$ considered the pre-dementia stage, stages $4-7$, the dementia stage.

\section{Analysis}

The analysis group comprised patients who completed the follow-up examination on the occurrence of depression and change in the cognitive functions among the subjects who satisfied the inclusion/exclusion criteria. The descriptive statistics on all the variables were presented, including the basic demographic information, medical history, comorbidity, medication history, occurrence and severity of depression, cognitive functions, and overall function level. The basic demographic information included the age, gender, height, weight, body mass index (BMI), and education level. For continuous data, the number of cases, the mean, and the standard deviation were presented, whereas for categorical data, the frequency and percentage were presented. The significance level for all the statistical tests was set at 0.05 , and two-sided tests were performed. All the p-values were presented with up to four decimal places, and $\mathrm{p}<0.05$ was considered significant. The figures with decimal places, including the mean, standard deviation, and percentage, were presented with up to two decimal places. Since this study was primarily an observational one, missing observations were processed as missing data in the analysis. For the recruited patients, a diagram was presented to help confirm both the number of subjects excluded from and those included in the analysis. Additionally, descriptive statistics (frequency and percentage) were presented on whether or not the subjects completed the study, along with information on the subjects who dropped out was also presented.

For the incidence of depression, the number of subjects and corresponding percentage were presented after the investigator, who was a psychiatrist, checked the occurrence of depression after 12 months of observation. A 95\% confidence interval was presented for the percentage. The incidence of depression was presented based on the investigator's judgment on whether or not clinically significant depressive symptoms were present. The frequencies and percentages of depression diagnosed with MINI-K and SGDS-K were separately suggested. To determine the consistency of the investigator's clinical judgment with the MINI-K and SGDS-K results on the incidence of depression, Cohen's kappa coefficients were presented. According to the interpretation method suggested by Landis and Koch, Cohen's kappa coefficients were interpreted as having had poor consistency $(0<\mathrm{Kappa} \leq 0.2)$, fair consistency $(0.2<$ Kappa $\leq 0.4)$, moderate consistency $(0.4<$ Kappa $\leq 0.6)$, substantial consistency $(0.6<\mathrm{Kappa} \leq 0.8)$, and good consistency $(0.8<$ Kappa $\leq 1) .{ }^{37}$

For the MINI-K, depending on the group of $\mathrm{AD}$ patients who developed depression and the group of $\mathrm{AD}$ patients who did not develop depression, the depression stage was suggested. Subsequently, the difference between the groups was analyzed using Fisher's exact test. The SGDS, MMSE-KC, and GDS scores at the baseline and after 12 months, and the descriptive statistics on the amounts of the changes from the baseline and after 12 months [the number of cases, mean \pm standard deviation, and median (range)], were presented. The significance of the difference between the groups in the amounts of changes from the baseline after 12 months was analyzed using Wilcoxon's rank sum test based on the normality test results.

To determine the factors that affect the incidence of depression, univariate logistic regression analysis and multiple logistic regression analysis were performed. In the univariate logistic regression analysis, the individual factors that independently affected the incidence of depression were determined at a 0.05 significance level. In the multiple logistic regression analysis, factors that affected the incidence of depression were determined using the stepwise variable selection method at a 0.05 significance level.

\section{RESULTS}

Among the 1,272 subjects enrolled in this study, 775 
(60.93\%) completed the 12-month follow-up observation and were included in the analysis. Of the 497 (39.07\%) enrolled subjects who did not complete the observation, 384 (77.26\%) failed in the follow-up examination, 32 (6.44\%) were transferred to another hospital, 37 (7.44\%) withdrew their consent to participate in this study, 10 (2.01\%) died, and $34(6.84 \%)$ had other reasons for not completing the observation, such as the transfer of the investigator to another hospital.

\section{Characteristics of the subjects}

With respect to the demographic information of the subjects, their average age was $76.43( \pm 7.20)$. Broken down by age group, they were mostly in their 70 s (655 subjects or $51.49 \%) ; 26$ subjects $(2.04 \%)$ were in their 50 s; 170 subjects (13.36\%) were in their 60 s; and 420 subjects (33.02\%) were in their 80 s or older. In terms of gender, majority (855 subjects or $67.22 \%)$ were female. As for the treatment type, 1,251 subjects (98.35\%) underwent outpatient treatment. Their average height, weight, and BMI were $155.78 \pm 9.72 \mathrm{~cm}, 55.74 \pm$ $9.97 \mathrm{~kg}$, and $22.94 \pm 3.28 \mathrm{~kg} / \mathrm{m}^{2}$, respectively. With respect to the subjects' levels of education, the average number of years of their education was $7.15( \pm 4.06)$, with $246(19.34 \%)$ of them illiterate.

Most of the subjects (642 or 50.47\%) had clinically important medical histories, including disease and surgery histories. In particular, 423 subjects (33.25\%) had hypertension; 178 (13.99\%), diabetes mellitus; 80 (6.29\%), hyperlipidemia; and $65(5.11 \%)$, major surgery histories.

At the start of this study, 1,185 subjects (93.16\%) were administered psychoactive drugs. Among them, 1,154 (90.72\%) were administered cognitive enhancers, with 1,082 (85.06\%) given acetylcholinesterase inhibitors; 110 (8.65\%), memantine or NMDA receptor antagonist; and 420 (33.02\%), other cognitive enhancers. Among the cognitive enhancers, donepezil was the most commonly used single-preparation drug (by 874 subjects or $68.71 \%$ ). A total of 185 subjects (14.54\%) took antidepressants; 225 (17.69\%), antipsychotic drugs; and 145 (11.40\%), anti-anxiety drugs. Among the antidepressants, selective serotonin re-uptake inhibitors (SSRIs) were the most widely taken (by 131 subjects or 50\%), followed by serotoninnorepinephrine reuptake inhibitors (SNRIs) (by 60 subjects or $23 \%)$. Twelve subjects $(<5 \%)$ took tricyclic antidepressants (TCAs). As for the antipsychotic drugs, the most widely taken were atypical antipsychotic drugs (99\%). More than half of the subjects (688 or $54.09 \%$ ) took a drug other than cognitive enhancers.

The average SGDS-K score, which assessed the severity of the depressive symptoms of the subjects at the start of this study, was $3.26( \pm 2.73)$ points. The MMSE-KC and GDS scores, which assessed the overall cognitive functions and severity of the function level of the subjects depending on the damage in their cognitive functions, were $16.85( \pm 5.43)$ points and $4.06( \pm 1.04)$ points, respectively (Table 1$)$.

\section{Comparison of the incidence of depression depending on the diagnostic methods (diagnostic consistency)}

Among the 1,272 $\mathrm{AD}$ patients included at the start of this study, the occurrence of depression was assessed in 775 sub-

Table 1. Subjects' demographic and basic information

\begin{tabular}{|c|c|c|}
\hline \multirow{2}{*}{$\begin{array}{l}\text { Demographic and } \\
\text { basic information }\end{array}$} & \multicolumn{2}{|c|}{ Total $(\mathrm{N}=1,272)$} \\
\hline & \multicolumn{2}{|c|}{$\mathrm{N}(\%)$} \\
\hline \multicolumn{3}{|l|}{ Age } \\
\hline Mean \pm SD & 76.43 & \pm 7.20 \\
\hline Median & \multicolumn{2}{|c|}{77.00} \\
\hline Range (min to $\max$ ) & 47.00 & 99.00 \\
\hline $50-59$ & 26 & $(2.04)$ \\
\hline $60-69$ & 170 & $(13.36)$ \\
\hline $70-79$ & 655 & $(51.49)$ \\
\hline Older than 80 years & 420 & $(33.02)$ \\
\hline \multicolumn{3}{|l|}{ Gender } \\
\hline Female & 855 & $(67.22)$ \\
\hline \multicolumn{3}{|c|}{ Inpatient/Outpatient classification } \\
\hline Inpatient & 12 & $(0.94)$ \\
\hline Outpatient & 1251 & $(98.35)$ \\
\hline Inpatient $\leftrightarrow$ Outpatient & 9 & $(0.71)$ \\
\hline \multicolumn{3}{|l|}{ BMI $\left(\mathrm{kg} / \mathrm{m}^{2}\right)$} \\
\hline Mean \pm SD & 22.94 & \pm 3.28 \\
\hline \multicolumn{3}{|l|}{ Number of years of education } \\
\hline Mean \pm SD & 7.15 & \pm 4.06 \\
\hline \multicolumn{3}{|l|}{ Concomitant drug } \\
\hline Yes & 1185 & $(93.16)$ \\
\hline Antipsychotic drug & 225 & $(17.69)$ \\
\hline Antidepressant & 185 & $(14.54)$ \\
\hline Anti-anxiety drug & 145 & $(11.40)$ \\
\hline None & 87 & $(6.84)$ \\
\hline \multicolumn{3}{|l|}{ SDGS } \\
\hline Mean $\pm S D$ & 3.26 & \pm 2.73 \\
\hline \multicolumn{3}{|l|}{ MMSE } \\
\hline Mean $\pm S D$ & 16.85 & \pm 5.43 \\
\hline \multicolumn{3}{|l|}{ GDS } \\
\hline Mean \pm SD & 4.06 & \pm 1.04 \\
\hline
\end{tabular}


jects after 12 months. Based on the investigator's clinical assessment, 103 of them had depression [13.29\%, 95\% confidence interval $(10.98,15.88)]$ (Table 2). The comparison of the characteristics of the subject group that developed depression and those of the subject group that did not develop depression showed no significant difference in their demographic information, including in their age, education, BMI, etc., except in their gender, as the proportion of females was significantly higher in the group that developed depression. In the case of the SGDS-K, which assessed the severity of the depression at the start of this study, there was no difference. There was also no difference between the groups in their MMSE-KC scores that assessed their cognitive functions. The GDS score, which assessed their overall function level due to cognitive impairment, was higher in the group that developed depression. The comparison of the groups in terms of their use of a psychoactive drug at the baseline depending on the occurrence of depression showed that in the group that developed depression, more subjects took antidepressants $(33.98 \%$ vs. $19.27 \%, \mathrm{p}<0.0001)$ or anti-anxiety drugs $(20.39 \%$

Table 2. Frequency of depression

\begin{tabular}{|c|c|c|}
\hline \multirow{2}{*}{$\begin{array}{c}\text { Occurrence of } \\
\text { depression }\end{array}$} & Total $(\mathrm{N}=775)$ & \multirow{2}{*}{$\begin{array}{c}\text { 95\% confidence interva } \\
\text { (lower-upper) }\end{array}$} \\
\hline & $\mathrm{N}(\%)$ & \\
\hline Yes & $103(13.29)$ & $(10.98-15.88)$ \\
\hline No & $672(86.71)$ & - \\
\hline
\end{tabular}

vs. $9.52 \%, \mathrm{p}=0.0010)$. For other drugs, there was no significant difference between the groups (Table 3 ).

To confirm the consistency of the results in terms of the occurrence of depression based on the investigator's judgment and the MINI-K and SGDS-K scores, Cohen's Kappa coefficients were presented. The incidence of depression assessed with MINI-K, in which a structured diagnostic method was applied, was 5.29\%. The incidence of depression at an SGDS-K score higher than 6 points was $19.87 \%$. In the diagnosis of depression assessed with MINI-K, it was found that major depressive disorder occurred in $1.68 \%$ of the subjects. Cohen's Kappa coefficients for the occurrence of depression assessed with MINI-K and SGDS-K were 0.38 and 0.21 , respectively, showing 'fair consistency' with the occurrence of depression based on the investigator's judgment (Table 4).

\section{Severity of depression and changes in cognitive functions due to the occurrence of depression}

Twelve months after the start of this study, the severity of depression and the differences in the changes in cognitive functions as well as the amount of changes were assessed, targeting the groups that developed depression and those that did not.

From the assessment of the stage of the depressive episode of the 103 subjects diagnosed with depression after 12 months using MINI-K, 11.65\% (12/103) were classified into the group with major depressive disorder; $3.88 \%$ (4/103) into the group

Table 3. Comparison of the characteristics of the group that developed depression and of the group that did not develop depression

\begin{tabular}{|c|c|c|c|c|}
\hline \multicolumn{2}{|c|}{ Demographic and basic information } & \multirow{2}{*}{$\begin{array}{l}\text { Group that developed depression } \\
\qquad(\mathrm{N}=103) \\
75.14 \pm 6.84\end{array}$} & \multirow{2}{*}{$\begin{array}{l}\text { Group that did not develop depression } \\
\qquad(\mathrm{N}=672) \\
76.21 \pm 6.96\end{array}$} & \multirow{2}{*}{$\frac{\mathrm{p} \text {-value }}{0.1430^{*}}$} \\
\hline Age & Mean \pm SD & & & \\
\hline & $50-59$ & $2(1.94)$ & $13(1.93)$ & $0.7807^{\dagger}$ \\
\hline & $60-69$ & $17(16.50)$ & $93(13.84)$ & \\
\hline & $70-79$ & $57(55.34)$ & $360(53.57)$ & \\
\hline & Older than 80 & $27(26.21)$ & $206(30.65)$ & \\
\hline Gender & Female & $80(77.67)$ & $446(66.37)$ & $0.0222^{\dagger}$ \\
\hline BMI $\left(\mathrm{kg} / \mathrm{m}^{2}\right)$ & Mean $\pm S D$ & $23.47 \pm 2.99$ & $22.75 \pm 3.30$ & $0.2564^{*}$ \\
\hline Education years & Mean \pm SD & $6.52 \pm 2.88$ & $7.11 \pm 4.10$ & $0.2119^{\ddagger}$ \\
\hline Baseline CE & Yes & $98(95.15)$ & $650(96.73)$ & $0.4153^{\dagger}$ \\
\hline Baseline AP & Yes & $24(23.30)$ & $106(15.77)$ & $0.0569^{\dagger}$ \\
\hline Baseline AD & Yes & $35(33.98)$ & $69(10.27)$ & $<0.0001^{\dagger}$ \\
\hline Baseline AA & Yes & $21(20.39)$ & $64(9.52)$ & $0.0010^{\dagger}$ \\
\hline SGDS & Mean \pm SD & $3.50 \pm 2.36$ & $3.25 \pm 2.52$ & $0.2632^{\ddagger}$ \\
\hline MMSE & Mean $\pm S D$ & $17.14 \pm 3.69$ & $16.95 \pm 5.31$ & $0.9877^{\ddagger}$ \\
\hline GDS & Mean $\pm S D$ & $4.27 \pm 0.89$ & $4.06 \pm 1.01$ & $0.0191^{\ddagger}$ \\
\hline
\end{tabular}

Missing data (persons): Group that developed depression, BMI (74); and Group that did not develop depression - BMI (316). *two sample ttest, ${ }^{\dagger}$ Pearson’s chi-squrare test, ${ }^{\ddagger}$ Wilcoxon’s rank sum test. BMI: body mass index, CE: cognitive enhancers, AP: antipsychotic drugs, AD: antidepressants, AA: anti-anxiety drugs, SGDS: Geriatric Depression Scale-Short Form, MMSE: Mini-Mental State Examination, GDS: Global Deterioration Scale 
with minor depressive disorder; and $14.56 \%$ (15/103) into the group with subsyndromal depression. Although they were diagnosed with depression based on the investigator's judgment, $69.90 \%$ (72/103) were classified into the group with 'no depressive episode.' On the other hand, $98.51 \%$ (662/672) of the subjects not diagnosed with depression after 12 months were classified into the group with 'no depressive episode.' The percentages of the subjects according to the stage of their depressive episode showed a statistically significant difference depending on the diagnosis of depression $(\mathrm{p}<0.0001)$ (Table 5).

The SGDS-K scores, which assessed the severity of depression in the group that developed depression, showed that the change in scores from the baseline after 12 months was statistically significant $(\mathrm{p}<0.0001)$. However, this was insignificant in the group that did not develop depression ( $\mathrm{p}=0.9497$ ). The amount of change in the SGDS-K scores showed a statistically significant difference between the groups $(\mathrm{p}<0.0001)$. In the MMSE-KC assessment of the overall cognitive functions, the changes in the scores from the baseline after 12 months were statistically significant in both groups $(\mathrm{p}=0.0448$ and $\mathrm{p}<0.0001$ ), but the amount of changes did not significantly differ ( $\mathrm{p}=0.4098$ ). In the case of GDS, which is an assessment tool for other cognitive functions and overall function level, scores showed a statistically significant difference between the groups at the baseline $(\mathrm{p}=0.0191)$. However, changes in the scores from the baseline after 12 months showed a statistically significant difference only in the group that did not develop depression $(\mathrm{p}<0.0001)$. The amount of changes did not significantly differ between the groups $(\mathrm{p}=0.8402)$ (Table 6).

\section{Factors in the occurrence of depression}

To investigate the risk factors in the occurrence of depression, the associations of the major demographic characteristics (gender, age, treatment type, and education level), medical history (diabetes mellitus, hypertension, and hyperlipidemia), drugs administered at the baseline (cognitive enhancers, antidepressants, antipsychotic drugs, and anti-anxiety drugs), severity of the depressive mood at the baseline (SGDS-K), and overall cognitive functions (MMSE-KC and GDS) with the occurrence of depression were analyzed.

In the univariate analysis, the incidence of depression showed a statistically significant difference between the groups in terms of the gender $(\mathrm{p}=0.0108)$, administration of an antidepressant at the baseline $(\mathrm{p}<0.0001)$, SGDS-K score $(\mathrm{p}=$ $0.0253)$, and GDS score ( $\mathrm{p}=0.0012)$. The incidence of depression among the female subjects was 2.261 times that in the

Table 4. MINI-K and SGDS depressive episode depending on the occurrence of depression

\begin{tabular}{|c|c|c|c|}
\hline \multirow{3}{*}{ Depressive episode } & \multicolumn{2}{|c|}{ Occurrence of depression (investigator's judgment) } & \multirow{3}{*}{ Kappa* } \\
\hline & Yes $(\mathrm{N}=103)$ & No $(\mathrm{N}=672)$ & \\
\hline & $\mathrm{N}(\%)$ & $\mathrm{N}(\%)$ & \\
\hline \multicolumn{4}{|l|}{ MINI-K } \\
\hline Yes & $31(4.00)$ & $10(1.29)$ & 0.38 \\
\hline Major depressive disorder & $12(1.55)$ & $1(0.13)$ & \\
\hline Minor depressive disorder & $4(0.52)$ & $3(0.39)$ & \\
\hline Subsyndromal depression & $15(1.94)$ & $6(0.77)$ & \\
\hline No & $72(9.29)$ & $662(85.42)$ & \\
\hline \multicolumn{4}{|l|}{$\mathrm{SGDS}^{\dagger}$} \\
\hline Yes & $43(5.55)$ & $111(14.32)$ & 0.21 \\
\hline No & $60(7.74)$ & $561(72.39)$ & \\
\hline
\end{tabular}

*Cohen's kappa coefficient, ${ }^{\dagger}$ diagnosed with depression when SGDS $\geq 6$. MINI: Mini-International Neuropsychiatric Interview, SGDS: Geriatric Depression Scale-Short Form

Table 5. Difference in the severities depending on the occurrence of depression (MINI-K)

\begin{tabular}{|c|c|c|c|c|c|}
\hline \multirow[t]{2}{*}{ MINI-K } & \multicolumn{2}{|c|}{$\begin{array}{l}\text { Group that developed depression } \\
\qquad(\mathrm{N}=103)\end{array}$} & \multicolumn{2}{|c|}{$\begin{array}{l}\text { Group that did not develop depression } \\
\qquad(\mathrm{N}=672)\end{array}$} & \multirow[t]{2}{*}{ p-value } \\
\hline & $\mathrm{N}$ & $(\%)$ & $\mathrm{N}$ & $(\%)$ & \\
\hline Major depression & 12 & $(11.65)$ & 1 & $(0.15)$ & $<0.0001^{*}$ \\
\hline Mild depression & 4 & $(3.88)$ & 3 & $(0.45)$ & \\
\hline Subsyndromal depression & 15 & $(14.56)$ & 6 & $(0.89)$ & \\
\hline No depressive episode & 72 & $(69.90)$ & 662 & $(98.51)$ & \\
\hline
\end{tabular}

*Fisher's exact test. MINI: Mini-International Neuropsychiatric Interview 
male subjects [95\% confidence interval (1.079 and 2.879)]. The incidence of depression in the subjects who took an antidepressant at the baseline was 4.498 times [95\% confidence interval $(2.790,7.254)]$ that of the subjects who did not. A one-point increase in the SGDS-K score at the baseline resulted in 1.111 times the incidence of depression [95\% confidence interval $(1.007,1.530)]$. A one-point increase in the GDS score at the baseline resulted in 1.539 times the inci- dence of depression [95\% confidence interval $(1.007,1.530)]$ (Table 7). For the multivariate analysis, using the stepwise variable selection method, multiple logistic regression analysis was performed based on the gender, administration of an antidepressant, and SGDS-K and GDS scores. The analysis results showed that the incidence of depression in the female patients was 2.145 times [95\% confidence interval (1.005, $2.752)]$ that in the male patients [95\% confidence interval

Table 6. Changes in the depression, cognitive functions, and severity of dementia depending on the occurrence of depression

\begin{tabular}{|c|c|c|c|}
\hline \multirow{2}{*}{ Assessment scales } & Group that developed depression $(\mathrm{N}=103)$ & Group that did not develop depression $(\mathrm{N}=672)$ & \multirow{2}{*}{ p-value } \\
\hline & Mean \pm SD & Mean \pm SD & \\
\hline \multicolumn{4}{|l|}{ SGDS } \\
\hline Baseline & $3.50 \pm 2.36$ & $3.25 \pm 2.52$ & $0.2632 *$ \\
\hline 12 months & $5.70 \pm 4.08$ & $3.30 \pm 2.64$ & \\
\hline Amount of change & $2.19 \pm 4.17$ & $0.05 \pm 2.38$ & $<0.0001^{*}$ \\
\hline $\mathrm{p}$-value & $<0.0001^{\dagger}$ & $0.9497^{\dagger}$ & \\
\hline \multicolumn{4}{|l|}{ MMSE } \\
\hline Baseline & $17.14 \pm 3.69$ & $16.95 \pm 5.31$ & $0.9877^{*}$ \\
\hline 12 months & $16.34 \pm 4.42$ & $16.19 \pm 5.57$ & \\
\hline Amount of change & $-0.80 \pm 3.73$ & $-0.76 \pm 3.32$ & $0.4098^{*}$ \\
\hline p-value & $0.0448^{\dagger}$ & $<0.0001^{\dagger}$ & \\
\hline \multicolumn{4}{|l|}{ GDS } \\
\hline Baseline & $4.27 \pm 0.89$ & $4.06 \pm 1.01$ & $0.0191^{*}$ \\
\hline 12 months & $4.38 \pm 1.14$ & $4.22 \pm 1.16$ & \\
\hline Amount of change & $0.11 \pm 0.88$ & $0.16 \pm 0.66$ & $0.8402 *$ \\
\hline $\mathrm{p}$-value & $0.2502^{\dagger}$ & $<0.0001^{\dagger}$ & \\
\hline
\end{tabular}

Amount of change $=12$ months-baseline. ${ }^{*}$ Wilcoxon's rank sum test, ${ }^{\dagger}$ Wilcoxon's signed rank test. SGDS: Geriatric Depression Scale-Short Form, MMSE: Mini-Mental State Examination, GDS: Global Deterioration Scale

Table 7. Analysis of factors in the occurrence of depression (univariate analysis)

\begin{tabular}{lccccc}
\hline \multicolumn{1}{c}{ Item } & Estimate & SE & \multicolumn{2}{c}{ OR $(95 \%$ confidence interval $)$} & p-value \\
\hline Gender & 0.816 & 0.320 & 2.261 & $(1.207,4.233)$ & 0.0108 \\
Age & -0.024 & 0.018 & 0.976 & $(0.942,1.012)$ & 0.1903 \\
Treatment type & 0.579 & 1.103 & 1.785 & $(0.205,15.507)$ & 0.5993 \\
Education level & 0.287 & 0.393 & 1.333 & $(0.617,2.880)$ & 0.4651 \\
Hypertension & 0.530 & 0.298 & 1.699 & $(0.946,3.049)$ & 0.0758 \\
Diabetes mellitus & 0.004 & 0.361 & 1.004 & $(0.495,2.038)$ & 0.9906 \\
Hyperlipidemia & 0.404 & 0.613 & 1.498 & $(0.450,4.984)$ & 0.5098 \\
Cognitive enhancers & -0.356 & 0.367 & 0.701 & $(0.342,1.438)$ & 0.3322 \\
Antipsychotic drugs & 0.135 & 0.349 & 1.145 & $(0.577,2.269)$ & 0.6989 \\
Antidepressants & 1.504 & 0.244 & 4.498 & $(2.790,7.254)$ & $<0.0001$ \\
Ant-anxiety drugs & 0.507 & 0.432 & 1.660 & $(0.712,3.870)$ & 0.2410 \\
SGDS & 0.105 & 0.047 & 1.111 & $(1.013,1.218)$ & 0.0253 \\
MMSE & -0.009 & 0.025 & 0.991 & $(0.944,1.041)$ & 0.7257 \\
GDS & 0.431 & 0.133 & 1.539 & $(1.186,1.996)$ & 0.0012 \\
\hline
\end{tabular}

Univariate logistic regression analysis. SE: standard error, OR: odds ratio, SGDS: Geriatric Depression Scale-Short Form, MMSE: Mini-Mental State Examination, GDS: Global Deterioration Scale 
Table 8. Analysis of factors in the occurrence of depression (multivariate analysis)

\begin{tabular}{lccccc}
\hline \multicolumn{1}{c}{ Item } & Estimate & SE & OR (95\% confidence interval) & $\mathrm{p}$-value \\
\hline Gender & 0.763 & 0.323 & 2.145 & $(1.138,4.042)$ & 0.0183 \\
SGDS & 0.118 & 0.049 & 1.125 & $(1.022,1.240)$ & 0.0168 \\
GDS & 0.425 & 0.135 & 1.530 & $(1.175,1.992)$ & 0.0016 \\
\hline
\end{tabular}

Multivariate logistic regression analysis. SE: standard error, OR: odds ratio, SGDS: Geriatric Depression Scale-Short Form, GDS: Global Deterioration Scale

$(1.005,2.752)]$, which was statistically significant $(\mathrm{p}=0.0183)$. Additionally, depending on the SGDS-K score at the baseline, the incidence of depression increased 1.125 times [95\% confidence interval $(2.957,7.921), \mathrm{p}=0.0168]$. Depending on the GDS score, it increased 1.530 times [95\% confidence interval $(1.147,3.033), \mathrm{p}=0.0016]$ (Table 8).

\section{DISCUSSION}

In our study, the incidence of depression that developed after one year in $775 \mathrm{AD}$ patients without depressive symptoms was $13.29 \%$, based on the clinician's judgment through investigation of the patient's medical history. The incidence of depression in $\mathrm{AD}$ differs depending on the method of measurement of the depression or its severity, but is mostly high. ${ }^{5}$ Studies on the incidence of depression in $\mathrm{AD}$ are few, while two related studies reported the incidence and prevalence of major depressive disorders. Weiner et al. ${ }^{10}$ reported the incidence of major depression as $0 \%$ in one year and $1.3 \%$ in two years in their first report. In their subsequent report (2002), the incidence was $4.7 \%$ in three years, which was about $1.6 \%$ annually, in one database. In another database, it was $2 \%$ in three years. ${ }^{11}$ This was attributed to the fact that they were all incidences of major depressive disorders. In this study, the incidence of major depressive episodes assessed using MINI was $1.68 \%$, similar to the aforementioned results. Payne et al. ${ }^{12}$ reported the incidence of depression in one year as 6.5\% using Cornell Scale for Depression in Dementia (CSDD). In our study, the incidence of depression in $\mathrm{AD}$ patients without depression one year later was 5.29\%, when more structured diagnostic criteria were applied; $13.29 \%$ based on the investigator's judgment; and $19.87 \%$ when the depression measurement was used, which showed relatively higher incidences. However, it could be thought that a similar result was produced in this study using MINI, a structured tool, because the CSDD used in the study of Payne et al. ${ }^{12}$ was an assessment tool specialized for dementia. Also, it is worth noting that because it included both patients and caregivers, its reliability and validity were high. Although the clinician's judgment revealed different diagnostic results from those of the structured diagnostic tools or depression scales, the diagnostic consistency was 'fair' (MINI-K: 0.38 and SGDS: 0.21). Therefore, in the diagnosis of depression in dementia patients with $\mathrm{AD}$, the assessment by the psychiatrist during consultation with the patient seemed appropriate. Depression may generally have a negative influence in $\mathrm{AD}$ on the cognitive functions or the overall function level, as well as the course of the disease, and degrade the quality of life of the patients or caregivers. It will be desirable to assess depression briefly through an interview with the psychiatrist and to take proper action in practice.

When the elderly suffer from depression, as it is associated with cognitive decline, their overall function level may decrease. Therefore, depression may affect the cognitive functions in $\mathrm{AD}$, which will directly affect the patient's function level. This clearly indicates that it is important to figure out associations among such factors. However, even though the incidence of depression is high in $\mathrm{AD}$ patients, studies on associations are insufficient compared to studies of the general elderly population. Studies of Dufouil et al. ${ }^{17}$ and Henderson et al. ${ }^{15}$ reported no marked association between depression and cognitive decline, while studies of Bassuk et al. ${ }^{16}$ and Chen et al. ${ }^{18}$ reported associations. Berger et al. ${ }^{19}$ observed an $\mathrm{AD}$ patient group with depression and an $\mathrm{AD}$ patient group without depression for three years and reported that depressive symptoms affected the cognitive decline at the start. A recent study reported emotional neuropsychiatric symptoms (NPS), such as depressive symptoms, as risk factors in advancement to severe $\mathrm{AD}{ }^{38}$ In the comparison of $\mathrm{AD}$ patients with depression after 12 months and AD patients without depression after 12 months in our study, the amount of changes in the MMSE-KC and GDS scores did not show a statistically significant difference during the study period. Although the amount of change in the scores from the baseline after 12 months did not show a significant difference between the two groups regardless of the diagnosis of depression, the change in the MMSE-KC scores during the study period showed a significant difference in the two groups (in both, $\mathrm{p}=0.0448, \mathrm{p}<$ 0.0001). This indicated that the cognitive functions in the $\mathrm{AD}$ patients declined over time. However, the change in GDS score was found to have been significant in the group that did not develop depression, which could be attributed to the significantly high GDS score at the baseline in the group that developed depression ( $p=0.0191$ ). Considering that the GDS score at the baseline in the group that developed depression 
after 12 months was high, it can be thought that occurrence of depression can be affected by the overall functions, including the cognitive functions, in $\mathrm{AD}$. Although previous studies reported various associations between cognitive functions and depression, this study showed that depression has a negative association with the cognitive function level of $\mathrm{AD}$ patients.

Generally similar to the elderly, depression in $\mathrm{AD}$ may directly influence the function level and the quality of life. Depression itself causes problems in treatment and care. Thus, assessing the factors in the occurrence of depression is important in dementia management. In this study, based on the univariate analysis to estimate individual risk factors of newly developing depression, a female gender, administration of antidepressants at the baseline, and high SGDS-K and GDS scores were found to affect depression. In the multivariate analysis, the administration of antidepressants was associated with the occurrence of depression, although this was not significant. This study was conducted among patients identified as not having had depressive symptoms based on the investigator's judgment and when MINI-K was used. However, $14.54 \%$ of the subjects were taking an antidepressant at the baseline. These subjects took an antidepressant due to depressive episodes before the study started. They were likely to keep taking the drug to prevent recurrence, even though symptoms improved. They might have taken an antidepressant based on the investigator's judgment that they had a relatively high risk of depression. Considering these assumptions, the incidence of depression in subjects who took an antidepressant at the baseline could be relatively higher than the incidence of depression in subjects who did not. As a result of the stepwise variable selection for multivariate analysis, a female gender and the SGDS-K and GDS scores at the baseline affected the occurrence of depression. Studies related to risk factors of depression in $\mathrm{AD}$ are very limited, but as many studies have consistently reported a significantly high frequency of depression in women, a female gender can be considered a relatively apparent risk of depression. ${ }^{39,40}$ Holtzer et al. ${ }^{41}$ reported the overall function level of dementia, not of the cognitive functions, as a risk factor associated with the onset of depression over time in $\mathrm{AD}$ patients without depression at the start of this study. In this study, the score for MMSE-KC, an assessment tool for cognitive functions, was not associated with the occurrence of depression. GDS, which assessed the overall function level, revealed an association with the occurrence of depression although it was based on cognitive functions. These results are somewhat consistent with those of previous studies.

Our study had limitations due to its nature as an observational study. During the study period, among the 1,272 subjects, 497 (39.07\%) dropped out. Still, this study is meaning- ful because the $\mathrm{AD}$ patients who underwent hospital treatment were investigated nationwide. Additionally, at the screening, the patients who were not depressed were included in the study using the clinician's judgment and the MINI-K assessment tool at the same time. During the assessment, depression was diagnosed using the clinician's judgment, and based on this, the risk factors were analyzed. The disadvantage can be overcome because the result of Cohen's Kappa coefficient calculation was 'fair.'

In conclusion, the incidence of depression in $\mathrm{AD}$ patients was $13.29 \%$ based on the clinician's judgment. The occurrence of depression did not affect the cognitive functions for 12 months. However, the gender and the overall function level, including the cognitive functions, seemed to have affected the occurrence of depression.

\section{Acknowledgments}

This study was sponsored by Eisai Korea Inc.

\section{REFERENCES}

1. Zubenko GS, Zubenko WN, McPherson S, Spoor E, Marin DB, Farlow $\mathrm{MR}$, et al. Acollaborative study of the emergence and clinical features of the major depressive syndrome of Alzheimer's disease. Am J Psychiatry 2003;160:857-866.

2. Berger AK, Fratiglioni L, Forsell Y, Winblad B, Backman L. The occurrence of depressive symptoms in the preclinical phase of AD: a population-based study. Neurology 1999;53:1998-2002.

3. Verkaik R, Nuyen J, Schellevis F, Francke A. The relationship between severity of Alzheimer's disease and prevalence of comorbid depressive symptoms and depression: a systematic review. Int J Geriatr Psychiatry 2007;22:1063-1086.

4. Starkstein SE, Jorge R, Mizrahi R, Robinson RG. The construct of minor and major depression in Alzheimer's disease. Am J Psychiatry 2005;162:2086-2093.

5. Olin JT, Katz IR, Meyers BS, Schneider LS, Lebowitz BD. Provisional diagnostic criteria for depression of Alzheimer disease: rationale and background. Am J Geriatr Psychiatry 2002;10:129-141.

6. Olin JT, Schneider LS, Katz IR, Meyers BS, Alexopoulos GS, Breitner JC, et al. Provisional diagnostic criteria for depression of Alzheimer disease. Am J Geriatr Psychiatry 2002;10:125-128.

7. Harwood DG, Barker WW, Ownby RL, Bravo M, Aguero H, Duara R. Depressive symptoms in Alzheimer's disease. An examination among community-dwelling Cuban American patients. Am J Geriatr Psychiatry 2000;8:84-91.

8. Snowden MB, Atkins DC, Steinman LE, Bell JF, Bryant LL, Copeland $\mathrm{C}$, et al. Longitudinal association of dementia and depression. Am J Geriatr Psychiatry 2015;23:897-905.

9. Ryu SH, Katona C, Rive B, Livingston G. Persistence of and changes in neuropsychiatric symptoms in Alzheimer disease over 6 months: the LASER-AD study. Am J Geriatr Psychiatry 2005;13:976-983.

10. Weiner MF, Edland SD, Luszczynska H. Prevalence and incidence of major depression in Alzheimer's disease. Am J Psychiatry 1994;151:1006-1009.

11. Weiner MF, Doody RS, Sairam R, Foster B, Liao TY. Prevalence and incidence of major depressive disorder in Alzheimer's disease: findings from two databases. Dement Geriatr Cogn Disord 2002;13:8-12.

12. Payne JL, Sheppard JM, Steinberg M, Warren A, Baker A, Steele C, et al. Incidence, prevalence, and outcomes of depression in residents of a long-term care facility with dementia. Int J Geriatr Psychiatry 
2002;17:247-253.

13. Reifler BV, Larson E, Teri L, Poulsen M. Dementia of the Alzheimer's type and depression. J Am Geriatr Soc 1986;34:855-859.

14. Kiloh LG. Pseudo-dementia. Acta Psychiatr Scand 1961;37:336-351.

15. Henderson AS, Korten AE, Jacomb PA, Mackinnon AJ, Jorm AF, Christensen $\mathrm{H}$, et al. The course of depression in the elderly: a longitudinal community-based study in Australia. Psychol Med 1997;27:119129.

16. Bassuk SS, Berkman LF, Wypij D. Depressive symptomatology and incident cognitive decline in an elderly community sample. Arch Gen Psychiatry 1998;55:1073-1081.

17. Dufouil C, Fuhrer R, Dartigues JF, Alperovitch A. Longitudinal analysis of the association between depressive symptomatology and cognitive deterioration. Am J Epidemiol 1996;144:634-641.

18. Chen P, Ganguli M, Mulsant BH, DeKosky ST. The temporal relationship between depressive symptoms and dementia: a community-based prospective study. Arch Gen Psychiatry 1999;56:261-266.

19. Berger AK, Fratiglioni L, Winblad B, Backman L. Alzheimer's disease and depression: preclinical comorbidity effects on cognitive functioning. Cortex 2005;41:603-612.

20. Jorm AF. Is depression a risk factor for dementia or cognitive decline? A review. Gerontology 2000;46:219-227.

21. Ownby RL, Crocco E, Acevedo A, John V, Loewenstein D. Depression and risk for Alzheimer disease: systematic review, meta-analysis, and metaregression analysis. Arch Gen Psychiatry 2006;63:530-538.

22. Palmer K, Berger AK, Monastero R, Winblad B, Backman L, Fratiglioni L. Predictors of progression from mild cognitive impairment to Alzheimer disease. Neurology 2007;68:1596-1602.

23. Diniz BS, Butters MA, Albert SM, Dew MA, Reynolds CF 3rd. Latelife depression and risk of vascular dementia and Alzheimer's disease: systematic review and meta-analysis of community-based cohort studies. Br J Psychiatry 2013;202:329-335.

24. Green RC, Cupples LA, Kurz A, Auerbach S, Go R, Sadovnick D, et al. Depression as a risk factor for Alzheimer disease: the MIRAGE Study. Arch Neurol 2003;60:753-759.

25. Reifler BV, Teri L, Raskind M, Veith R, Barnes R, White E, et al. Double-blind trial of imipramine in Alzheimer's disease patients with and without depression. Am J Psychiatry 1989;146:45-49.

26. Association AP. Diagnostic and Statistical Manual of Mental Disorders. Washington DC: APA; 1994.

27. McKhann G, Drachman D, Folstein M, Katzman R, Price D, Stadlan EM. Clinical diagnosis of Alzheimer's disease: report of the NINCDSADRDA Work Group under the auspices of Department of Health and Human Services Task Force on Alzheimer's Disease. Neurology 1984;34:939-944.
28. Yoo SW, Kim YS, Noh JS, Oh KS, Kim CH, Namkoong K, et al. Validity of Korean version of the Mini-International Neuropsychiatric Interview. Anxiety Mood 2006;2:50-55.

29. Bae JN, Cho MJ. Development of the Korean version of the Geriatric Depression Scale and its short form among elderly psychiatric patients. J Psychosom Res 2004;57:297-305.

30. Lee JH, Lee KU, Lee DY, Kim KW, Jhoo JH, Kim JH, et al. Development of the Korean version of the Consortium to Establish a Registry for Alzheimer's Disease Assessment Packet (CERAD-K): clinical and neuropsychological assessment batteries. J Gerontol B Psychol Sci Soc Sci 2002;57:P47-P53.

31. Reisberg B, Ferris SH, de Leon MJ, Crook T. The Global Deterioration Scale for assessment of primary degenerative dementia. Am J Psychiatry 1982;139:1136-1139.

32. Sheehan DV, Lecrubier Y, Sheehan KH, Amorim P, Janavs J, Weiller E, et al. The Mini-International Neuropsychiatric Interview (M.I.N.I.): the development and validation of a structured diagnostic psychiatric interview for DSM-IV and ICD-10. J Clin Psychiatry 1998;59(Suppl 20):22-33;quiz 34-57.

33. Organization WH. The ICD-10 Classification of Mental and Behavioural Disorders: Clinical Descriptions and Diagnostic Guidelines. Geneva, Switzerland: World Health Organization; 1992.

34. Yesavage JA. Geriatric Depression Scale. Psychopharmacol Bull 1988;24:709-711.

35. Alden D, Austin C, Sturgeon R. A correlation between the Geriatric Depression Scale long and short forms. J Gerontol 1989;44:P124-P125.

36. Folstein MF, Folstein SE, McHugh PR. "Mini-mental state”. A practical method for grading the cognitive state of patients for the clinician. J Psychiatr Res 1975;12:189-198.

37. Landis JR, Koch GG. The measurement of observer agreement for categorical data. Biometrics 1977;33:159-174.

38. Peters ME, Schwartz S, Han D, Rabins PV, Steinberg M, Tschanz JT, et al. Neuropsychiatric symptoms as predictors of progression to severe Alzheimer's dementia and death: the cache county dementia progression study. Am J Psychiatry 2015;172:460-465.

39. Liu CY, Fuh JL, Teng EL, Wang SJ, Wang PN, Yang YY, et al. Depressive disorders in Chinese patients with Alzheimer's disease. Acta Psychiatr Scand 1999;100:451-455.

40. Usman S, Chaudhary HR, Asif A, Yahya MI. Severity and risk factors of depression in Alzheimer's disease. J Coll Physicians Surg Pak 2010;20:327-330.

41. Holtzer R, Scarmeas N, Wegesin DJ, Albert M, Brandt J, Dubois B, et al. Depressive symptoms in Alzheimer's disease: natural course and temporal relation to function and cognitive status. J Am Geriatr Soc 2005;53:2083-2089. 